\title{
Understanding and Enhancing the Role of the Mass Media in Evolutionary Psychology Education
}

\author{
Maryanne L. Fisher • Daniel J. Kruger • \\ Justin R. Garcia
}

Published online: 6 January 2011

(C) Springer Science+Business Media, LLC 2011

\begin{abstract}
Mass media has always been a prominent source of science information for the general public, and more so than academic journals. The diversification of media with specialized online outlets and the participatory nature of the Internet have opened opportunities, as well as challenges, for researchers and educators. This paper represents our attempt to address this issue with respect to human evolutionary behavioral sciences, and suggest ways to successfully navigate interactions with the mass media for effective evolutionary education. We briefly review how one can interact with the mass media for educational purposes, focusing on how best to situate one's research within evolutionary theory. We describe our own experiences and those of other academic colleagues who have received mass media attention, noting both positive and negative results. We also provide specific tips on how to best interact with various forms of media.
\end{abstract}

\footnotetext{
M. L. Fisher $(\bowtie)$

Department of Psychology, Saint Mary's University,

923 Robie Street,

Halifax, NS B3H 3C3, Canada

e-mail: mlfisher@smu.ca

D. J. Kruger

School of Public Health, University of Michigan,

Ann Arbor, MI, USA

e-mail: djk2012@gmail.com

J. R. Garcia

Departments of Biological Sciences and Anthropology, and Institute for Evolutionary Studies, Binghamton University, Binghamton, NY, USA

e-mail: justin.r.garcia@gmail.com
}

Keywords Mass media $\cdot$ Education $\cdot$ Evolution . Interviews $\cdot$ Experiences

Over the past decade, educators have increasingly recognized the need for the development of evolutionary-based curriculum at the university and high school levels (O’Brien 2009; Wilson 2007). In some cases, universitylevel scholars are trying to directly reach teachers in an effort to help them shape their curriculum so that it reflects sound, scientific principles (e.g., Purrington 2009). This need for assistance is not trivial. For example, Berkman et al. (2008) surveyed American high school biology teachers and found that one in eight teaches creationism as a viable alternative to evolutionary theory, and that the majority only spend between three and fifteen hours covering evolution. Most teachers spend even less time (i.e., no more than five hours) on human evolution. Berkman et al. (2008) suggest that certification standards need to be raised to ensure that biology teachers are properly prepared to teach evolutionary theory, and that they do not allow personal religious views to prevent them from educating students.

This attention can be viewed as partly in reaction to the intrusion of non-scientific perspectives in the science classroom, and partly proactive by ensuring that future scientists and other students accurately comprehend the basics of scientific thought. Indeed, the recent formation of the Evolutionary Studies (EvoS) Consortium indicates that there is much interest amongst scientists in ensuring that evolutionary theory is sufficiently and accurately represented in higher-education pedagogy. The EvoS Consortium initiative is impressive, considering that it provides a unifying network that spans multiple universities, includes various fields of study, and has led to the creation of an academic journal (see Wilson et al. 2009). 
Although these efforts to address pedagogical needs within the educational system are important, they are limited to current students, and presumably, students who are initially open to the ideas of evolution. Those who are not students, or who have not been formally exposed to evolutionary theory, are often overlooked. Thus, to address this core issue, we focus on the activities that an individual evolutionist can do to educate beyond the university community. We argue that one of the best means of broad educational outreach for evolutionary theory is to use mass media outlets. Compared to the discourse on how to properly educate students, there has been substantially less attention dedicated towards educating the general public about evolution, aside from some impressive popular trade books on the topic (e.g., Evolution for Everyone by Wilson 2007, The Greatest Show on Earth by Dawkins 2009). Indeed, the mass media is a seemingly overlooked vehicle for evolutionary researchers to present their ideas and findings to larger audiences.

There are three key points to this paper. We begin by briefly presenting various views to show how one can interact with the mass media for educational purposes; we focus this section on the debate surrounding how best to situate one's research within evolutionary theory. Second, we use personal experiences, both our own as well as those of other academics, to highlight the ways in which human evolutionary-based research has received mass media attention, and some of the outcomes of that attention. These experiences have been both positive and negative, but ultimately reflect how media attention is an effective way for the field to receive attention. Third, we provide some "tips," again relying on our own experiences and those of other academics, for readers who wish to begin interactions with media. In particular, we discuss how to overcome those obstacles, by working with the mass media.

\section{Interacting with the Mass Media to Reach Educational Goals}

Interacting with the media can be a very valuable activity for evolutionary scholars, as it has the potential to impact the general public. When a scholar conducts an interview, she or he not only represents her or himself, but also the academic institution, and very often, the field itself. Thus, it is vital that the media reports are accurate and professional. Perhaps more importantly, however, is the fact that media reports allow the public to keep informed about contemporary scientific findings, and receive an "education" about recent research. We propose that this outcome should remain the single most important reason for researchers to share their work with the media, and to ensure that the reports are as accurate and correct as possible. Mass media represents a valuable tool for researchers to share their findings to an otherwise unreachable audience.

Evolutionary psychology has received a great deal of media attention with respect to other disciplines. This occurrence is likely due to the fact that discussions of "human nature" are a hot topic both within and beyond academia. The underpinnings of human nature are vigorously debated within the ivory tower, and elsewhere. Many evolutionists may have experienced these debates in their classrooms, or among friends and family, as individuals are captivated by the need to explain, comprehend, and perhaps legitimize their own thoughts and behaviors. Therefore, it is easy to see why the media are often already receptive to the idea of wanting to understand human nature. As a consequence, researchers do not have to generate interest among audience members, but instead, provide specific research findings that might be intriguing or help people understand the causes of their own behaviors.

We asked David Buss, a well-known evolutionary psychologist and Professor of Psychology at the University of Texas, about his perspective on working with the media. His response echoed our view:

As scientists, many of whom are funded by the public, we have an obligation to provide the products of science out to the public, not just the academics who have access to scientific journals. There is a range in quality of media outlets, from the New York Times to tabloids. These outlets will vary in the accuracy and extent of coverage. It is important to make sure that the reporting is as accurate as possible (personal communication).

The American public seems caught in the debate between those who believe in evolution and those who do not. Some academics, such as Richard Dawkins (Oxford University Emeritus Chair for the Public Understanding of Science), have forcefully argued in favor of the reality of evolution. In his book, The God Delusion, Dawkins (2006) is ubiquitously anti-creationism, and as a consequence, likeminded individuals primarily read his work.

If one hopes to reach a different audience, such as the lay public, a non-combative approach to the evolution-creationism debates may be useful. This tactic is especially true for researchers working in the area of human evolutionary behavioral studies (see Garcia et al. 2011). An additional strategy is to discuss evolutionary-based research in the media, but without explicitly stating it is evolutionary in nature (often jokingly referred to as not "using the Eword"). For example, one can talk about the strategies of human ancestors two million years ago, or how all the great apes, including humans, share certain cognitive traits, without necessarily evoking an anti-evolution response. Although these types of statements are openly in support of 
evolutionary arguments, individuals embroiled in the evolution-creation debate and falling alongside with the creationist sympathizers may not be "turned off" as quickly to the findings of the study. That is, by placing the study within the framework of science in general, and not evolution specifically, the findings might reach a broader audience. We recognize that this approach may not be ideal in terms of accurately disseminating scientific knowledge, but we also strongly encourage the education of scientific principles to be done as an incremental process, mirroring the process of science itself.

Others, however, have the opposite advice to offer. Wilson (2007) advocates presenting the public with the principles of evolutionary theory and allowing individuals to experience how much of their everyday life can be understood in light of this framework. Similar views were expressed during an interview with the internationally recognized anthropologist Helen Fisher, Research Professor of Anthropology at Rutgers University, and Chief Scientific Advisor to Chemistry.com. She stated:

One thing I always do is use the term evolution when I speak to the press. I don't explain evolutionary psychology. I just do evolutionary psychology. The press is very receptive to this perspective. Unlike many academics who resist this biological, evolutionary approach, the press seeks it. They are looking for a broader, deeper understanding of human behavior and I rarely find anyone from the press who has a problem with the idea that much of human behavior has evolutionary roots. The nature/nurture controversy still lives in academia, but most people in the press either don't know about this issue, or have moved beyond it. Indeed, with the exception of book reviewers, I find that most members of the press come to me with an impressively open mind (personal communication).

Thus, although one can effectively use the media to reach an audience that might otherwise not have access to evolutionary-based research findings, it remains debatable how much one should best situate the work within the evolutionary framework.

One might think that how the work is situated would be particularly important for maintaining academic credibility. To explore this issue, we asked several established scholars about their experiences; specifically, we asked how their colleagues and peers react once their research findings are incorporated into the mass media. Helen Fisher highlighted how feedback can stem from particular colleagues but not others:

Actually, I get a mixed response. I get some very positive feedback at times. But it always seems to be from people in disciplines other than anthropology.
Psychologists, sociologists, biologists, neuroscientists, psychiatrists, and therapists have expressed extreme interest in my brain scanning work. And people in the business community, psychiatry and couples therapy are often highly enthusiastic about my work in the biology of temperament. But I rarely hear from anthropologists. They never invite me to speak at their professional organizations; rarely invite me to speak to colleagues or universities; rarely review my books; and almost never come to my public lectures (personal communication).

This sentiment was partly shared by Glenn Geher, Professor and Chair of Psychology at SUNY New Paltz, founder of the NorthEastern Evolutionary Psychology Society, and co-founder of the EvoS Consortium:

There seems to be something of a divide-with a lion's share of colleagues responding positively to media attention regarding my work. However, there are clearly significant pockets of resistance to evolutionary studies within academia, and academics who strongly identify as against evolutionary studies applied to human behavior tend to respond a bit negatively to some of the media attention to my work (personal communication).

It seems that most academics recognize that the media will rarely be able to fully explore the issues presented in an article, for example, and consequently, will rarely criticize someone for not directly positioning the research in a certain way. Instead, oversight or criticism apparently stem from a systematic basis, such as being from a different discipline or having incompatible assumptions about "human nature."

\section{Personal Experiences with the Media}

Personal experiences are an indirect way to provide a "snapshot" of what a scholar might expect by working with the media. Two of us (Fisher and Kruger) began our relationships with the media quite unexpectedly. We presented our research on male mating strategies at the 2003 meeting of the American Psychological Association in Toronto, Canada (Fisher et al. 2003). Our presentation was selected for a special session where reporters were invited to attend. The focus of that research, romantic relationships, is certainly an interesting topic for the general public, though it likely helped that the first author was at the time a graduate student at a local university. We were delighted and a little surprised when a reporter expressed interest in talking with us. An article describing our research ran in a few Canadian newspapers, and was then 
noticed by other reporters. Other media outlets then interviewed us, including the New York Times. After this coverage, the story made the jump from print media to television.

Our initial foray into media coverage is representative of a common pattern. Thousands of research studies are published; many of these are very interesting to other academics but may not garner media attention. The sad fact is that most articles are never noticed outside of the physical or virtual halls of academia. Yet, once a study makes it into the news, interest will likely spread to other media outlets. It appears that reporters to some extent rely on other mass media sources for the latest contributions to science, and only rarely seek out their own, brand-new story. Additionally, researchers who have been previously covered in the media will sometimes be contacted by journalists to comment on another study or contemporary issue.

Another example comes from a study on hook-up behavior (uncommitted sexual experiences) on college campuses (Garcia and Reiber 2008). Although this work received the attention of a variety of journalists, from local newspapers to writers at Vanity Fair and Psychology Today, the most effortful interactions were in a student newspaper on the campus where the study was conducted. The paper had a general policy of not providing outside parties with the articles before they were sent to print, but the first author of the study also had a general policy of not granting interviews unless given the opportunity to later fact and quote check before the piece is printed. Although this situation quickly resolved itself, and the researchers were pleased with the student interest on campus, it was important to note that after an interview is conducted, it can often be difficult to be allowed to double check work. As an aside, the school newspaper's article directly led to more undergraduate research assistant applications that semester, and since then there has been a steady flow of top-quality students available to work in their laboratory.

One of the most negative experiences a researcher can have is when the general public poorly receives one's work. Ideally, instead of making the comments flippantly or of a personal nature, people would take the time to criticize the work on justified grounds, such as proposing precisely how the methodology is flawed, or explaining why the conclusions are overstated. In the age of the Internet everyone can be a critic and often remain anonymous, which seems to lead to more negative comments. Researchers may discover criticisms of their work posted on weblogs (i.e., blogs) or discussion lists, often from individuals with no academic credentials and/or peer-reviewed publications. Sometimes these commentaries will offer valid critiques, but often these reactions are riddled with misunderstandings, and many seem to be based on media coverage rather than the original article describing the study.
Some researchers have determined that responding to blog posts or other online discussions is not an effective use of time. For example, Doug Kenrick, Professor of Psychology at Arizona State University, deactivated the commentary section on his Psychology Today blog because the additional content did not bring sufficient additional value. Others consider selective engagement of online critics to be useful, especially to curb the repetition of misconceptions or unfair criticisms. The key may be selective and strategic engagement. Given the vast number of bloggers, one could not possibly keep up with all blogs, or even all posts in potentially relevant blogs, and still be academically productive.

Science news blogs with large and professional readerships may be most worthy of one's time investment, as they tend to contain a variety of findings in one outlet. Scholars who are interested in promoting evolutionary education should try to intervene early in response to faulty criticisms in order to prevent them from being exponentially perpetuated in other blogs. At the same time, one must remember that anything posted on the Internet is virtually permanent, so comments posted on the Internet will have durability. It is also important to remain professional and avoid ad hominem attacks, even if other posters are unprofessional; it may be best to wait a brief period before responding to reduce the likelihood of responding inappropriately. Also, one should considering writing a concise and focused response that is supported by evidence, referring readers to other sources of evidence (especially those available to the public online). Writing a comprehensive treatise would likely be ineffective, as most readers will not dedicate the time to read the additional material. Finally, once a response has been posted, it may not be necessary to reply to every subsequent comment. Replying to every post can be time demanding, especially if there are a large number of back-and-forth exchanges. Also worth noting is that many sites and discussion groups are plagued by "trolls" who amuse themselves by irking others, rather than having a genuine interest in furthering knowledge.

In our discussion with Helen Fisher, we asked about her experiences working with the media, specifically in how accurate the media reports tended to be. Her response highlights some of the positives and negatives involved when working with the media:

It is mixed. The coverage of my work isn't always better in high-quality media outlets, either. On live $\mathrm{TV}$, of course, I can control what I say. But in all other media avenues, I have to hold my breath. Sometimes a very fine publication like the New York Review of Books, the New York Times Book Review or the New Yorker invites someone to review my material who knows nothing about science and I get a review that lacks the contextual understanding of the issues I am 
discussing. Instead, they comment on minor points, often with uneducated criticisms, and fail to do an interesting review of the far more relevant points I am tackling. And some publications just make genuine mistakes because they know nothing about the topic and garble the data. But there are many nice experiences too. The Week always does an excellent job, because they hire knowledgeable reviewers, as does Science News and other publications "in the know," so to speak. The women's and men's magazines, such as Men's Health and Cosmopolitan, have fact checkers. So I am shown statements I have made to the journalist, and they respect my changes. But these publications must reduce complex arguments to simple, short statements, so even with my editing, the final copy can appear bald, lacking the nuance I far prefer. Given this uneven media coverage, I long ago decided to NOT read much of what is said about me and my work. When it's bad, it makes me anxious, sad and embarrassed. And I know I must continue speaking to the press because I believe in public education. So I keep myself fairly ignorant of much of the media coverage about me. I get more sleep this way (personal communication).

Either way, media attention can be both extraordinarily positive and overwhelmingly devastating. In general, however, there are many worthwhile positives, and in our opinion, the benefits far outweigh the costs. In addition to the obvious use of media for educating the public, it also enables universities to justify expenses while receiving endorsement for hiring a researcher. Perhaps most importantly for researchers, it allows other academics and interested parties to learn about the findings, which can inspire collaborations, followup studies, or consulting work. It can also serve as a way to advertise a book that one has authored.

It is worth noting that the amount of time one puts into interacting with the media is, like most things, a cost-benefit trade-off. Indeed, many of us will experience the reality of spending hours corresponding with journalists, planning an interview, and sharing useful information, only to find out one's quote was removed from the article during final editing. This wasted investment of time and energy can happen, and has happened to many of us who have interacted with media. Sometimes a thick skin and persistence are the most important things for scientists working with the mass media.

\section{Tips on Working with the Media}

There are various ways to initiate an interaction with the media, depending on a number of factors, such as the journal the work was published in, the topic of the paper, or one's energies to control the released information. Thus, an overview of the ways that media relations can work might be productive and illuminating for those who wish to undertake interactions with the media.

There are essentially four "individuals" involved in the system: the researcher, the researcher's academic institution, the journal, and the media outlet. It is important to note that researchers ultimately have the right to turn down offers of interviews, although the media may still report on the work. In many cases, media will not ask the researcher for comment, and instead rely upon the interpretation of their internal science writers, or simply pick up the facts from existing media reports.

Presuming the media does ask the researcher for an interview, it might be best to comply. Although interviews take time and effort, for which one might feel unrewarded, it helps ensure the accuracy of the final report. Interviews can be completed in an assortment of ways, including by telephone, e-mail, in-person or other means such as Skype. Occasionally, a researcher will be asked to conduct a live radio or television interview, in which case it might be possible to ask for a copy of potential questions beforehand. Although these can be nerve-wracking and there is no chance to retract a comment, they can also be great fun. Call-in shows can be very challenging, as the researcher does not know what questions will be asked, and there is minimal time to collect one's thoughts.

Researchers should be aware that the media will attempt to digest the results of a project to make them understandable and captivating to the general public. This process may result in catchy headlines, as well as inferences and implications that the researchers might not have made themselves. Thus, it is often wise to pre-digest one's study and findings, and present them in a way that is easily understandable, as well as accurate. Once a catchy tagline gets established in the media, it will be perpetuated by other outlets. We advise researchers to give reporters as much content as possible to help them cover the study accurately.

Regardless of the form of the interview or media report, aside from "live" situations, there may be a chance for a researcher to have the final say on the report. If the researcher is really concerned with accuracy, she or he can stipulate before the interview is conducted that it will be necessary for her or him to review and approve the final copy before it is released. These types of agreements are often not well received by the media, as they are often seeking to be the first to report on a finding, and do not want to have to delay publication until a researcher is satisfied. Moreover, reporters might agree to this stipulation but then not comply.

The importance of "having the final say" cannot be overestimated, though. When we asked Todd Shackelford, Professor and Chair of Psychology at Oakland University and Editor of Evolutionary Psychology, about how accurate 
he thought media reports were, he responded, "Generally, extremely accurate, in part because I tend not to grant interviews unless I have the opportunity to fact check the article before publication."

We asked the same question to Glenn Geher; his response suggested the positive role of student press:

It varies-honestly, probably the most accurate article related to my work was written by SUNY New Paltz undergraduate Corinna Ridgeway for SUNY New Paltz's The Little Rebellion-an alternative student newspaper. Most articles tend to get the gist of it right, while getting some of the details wrong. One article of mine a few years back was all about resistance to evolutionary studies from the far left-and the editor of the newspaper made the relevant sub-headline "Conservatives Stonewall"-as if the whole point were about the conservative resistance to evolution...so the accuracy issue is definitely something that needs to be considered! (personal communication)

While on the topic of having the final say before an article goes to print, it should be clear that a researcher must know the work in great detail prior to conducting a media interview. Sometimes interviewers seemingly have an agenda about how they want to slant the study to make it maximally interesting to the public. Once, when an author of this paper (Fisher) was interviewed by a Canadian national paper, the reporter repeatedly stated, "So what you are saying is..." and inserted an entirely incorrect, and potentially dangerous, conclusion of the work. Fisher corrected her on several occasions and finally replied that the reporter was obviously misunderstanding the work, and that she needed to see a final copy of the report before it was published. She then immediately wrote to the newspaper editorial staff and notified them of this issue, to ensure compliance.

On another occasion, one of the researchers (Garcia) was on a live radio show regarding romantic relationships and was repeatedly asked to dispense advice. Garcia made it clear multiple times that he was not a counselor or clinician, or even a psychologist by training. Instead, his research focused on "how come" not "how to" and consequently, while he could provide information to help explain people's behaviors and reactions, he was not in a position to tell people how to cope with issues of love. This issue is an important point of consideration; when interacting with the media it might be useful to keep in mind that one should be humble about one's limitations. Academics must be careful to not overstep themselves with the media, both in the best interest of the public and one's own future career.
Of course, these issues all arise after one has begun interacting with the media. But, how does one initiate these interactions? An effective and easy way to initiate media interactions is to contact the media relations office at one's academic institution. This office may be very small and handle a variety of tasks. On the other hand, especially at larger institutions, the office can be quite sizeable and a researcher will be assigned a person who will handle all aspects of media interactions. This resource is highly valuable, as they will assist with the writing of a press release that they will then distribute using their pre-existing contacts with local and national media outlets. In some cases, they will personally contact individual reporters to inform them of the work and to establish interviews. In many instances it is wise to work through these offices, as it allows the university to document one's efforts to work with the media and it is a source of often knowledgeable professionals. As well, it might help prevent an onslaught of media requests, given that there is a contact person other than the researcher. Researchers can also provide the office a list of the types of interviews she or he is willing and not willing to perform. For example, one may wish to avoid certain radio shows (e.g., a show that is oriented towards a particular audience and known to be hostile) or live interviews, and informing the media relations office of this decision may save the researcher time and energy. Media reports that draw attention to the university are viewed as advertising revenue; a story that is picked up by the international media can be valued as over a million dollars of free advertising (personal communication, York University Media Relations 2004).

The journal in which the work is published will greatly influence how widespread the media attention becomes, as well as whether it is noticed at all. This variance is not entirely related to the size and longevity of the journal, but is heavily influenced by the presence of a media relations office or officer who is associated with the journal. Larger, more established and popular journals (i.e., Nature, Science, Proceedings of the Royal Society of London, British Medical Journal) tend to have a media office, such that a staff member will be assigned to personally interact with the researcher. That individual will often contact the researcher directly if the work is perceived to be media-worthy, and work with her or him to generate a press release. This release is then distributed by the journal to various media outlets, and the media can use that release to generate the story, or is invited to contact the researcher or the institution's media office. Smaller journals might instead have a media relations officer who will work with researchers who wish to have media pay attention to their paper. Journals profit from having the media report on the work, as it brings attention 
to the journal itself, and hence, it is worthwhile for them to help researchers do well in this regard.

If one hopes to use media to educate, then it is critical to think about what the media needs to craft an accurate yet interesting story for their audience. An easy issue to remember is that reporters often desire a short "soundbite" that is not laden with technical jargon and gets to the heart of the matter. One concern that researchers might have is how their academic peers will think about the report, especially a soundbite that is without context. In our experience, most academics recognize that the media are not going to provide the full context of the soundbite, and that the researcher rarely has control over what is actually reported. Instead, if someone in the audience is interested, she or he will hopefully be provided with enough information to track down the actual publication where the work was presented. This issue is another point of consideration; researchers who wish fellow academics to locate the article (assuming it was an article) should provide the name of the journal, the names of all co-authors/coresearchers along with their institutional affiliations. Typically this information is included by reporters if it is provided by researchers during an interview.

An additional strategy that researchers can use to generate media interest is to personally inform reporters of one's latest findings. Once a researcher has worked successfully with the media, reporters might suggest that the researcher contact them personally if she or he has any newly released work. One can keep a contact list of reporters who have previously covered one's work and forward them additional press releases.

Last, it is crucial that researchers who are interacting with the media maintain an open and professional dialogue. There are a variety of reasons for why this is important, such as representing oneself well or ensuring the research is well explained and hence, accurately reported to the public. One less obvious reason is that a positive dialogue that is professional yet warm might minimize any discomfort scholars may have in this process. If both the reporters and researchers appreciate each other's involvement, the process might be quite pleasant. This point is well made by David Sloan Wilson, SUNY Distinguished Professor of Biological Sciences and Anthropology, and Director of the Institute for Evolutionary Studies at Binghamton University. While addressing a popular critique of research, he wrote in one of his Huffington Post blogs, titled "Evolutionary Psychology and the Public Media: Rekindling the Romance":

As for the public media, covering science must be one of the toughest journalistic assignments. First, one must understand the nature of the scientific process in general terms. Then, one must master the specific topic that is being reported. Finally, one must convey what is genuinely newsworthy to a general audience - the fair shots - while avoiding the cheap shots that get people's attention but become part of the problem in the long run. (http://www.huffingtonpost.com/david-sloan-wilson/ evolutionary-psychology-a_b_220545.html) (personal communication)

\section{Discussion}

The aim of this paper was to encourage evolutionary-based researchers to work with the media in an attempt to educate the public about recent findings. We reviewed some of the issues with situating one's work within an evolutionary framework, and then possible positive and negative outcomes of, and experiences with, media attention. Finally, we provided "tips" for working with the media, in the hopes that readers will be better able to provide the necessary information to produce accurate media reports. It is important to note that although we focus on empirical research leading to a specific finding that is published in a scientific journal, we believe that the same principles apply to scholarly books, theoretical papers, and conference work, and thus, hopefully all evolutionary scholars can apply at least some of the advice we provided.

One issue that we did not review in this paper concerns the type of research mass media seems most interested in covering. In our experiences, research findings that pertain to the foundations of human behavior seem particularly intriguing to reporters and the public. Topics such as mating strategies, mate preferences, parenting, food choice, sleep, helping behavior, friendships, and war, just to list a few, are matters that hold appeal to almost everyone. Evolutionary psychologists have it easy in this regard; what we study is fundamentally of interest to the media, and by the general public.

Although we emphasize the use of media for reaching groups who might otherwise not have access to evolutionary-based findings, we should note that the effects do reach the university classroom. As stated by Todd Shackelford:

Media coverage as best I can tell has a notable positive effect on class enrollment and student interest in evolutionary theory. In an evolutionary psychology class of 50 students, perhaps 3-5 will explicitly tell me they enrolled in the class after seeing a magazine or newspaper or Internet article on evolutionary psychology, in general, or one that cited my own work, in particular (personal communication).

Another way that media reporting can impact on the university classroom, suggested by Shackelford, is when 
the course instructor's work is seen in the media by students. This point was expanded upon by Glenn Geher:

They eat it up like kids eating chocolate on Halloween! Honestly, students definitely seem to respond positively to seeing their professor's work cited in the media - and it gets them motivated at a whole other level. If you're a student in class and your professor's work is being quoted in major newspapers or magazines, you're probably like "oh, people actually care about this stuff-let me pay attention!" Also, students really appreciate the opportunity to do research with me-and I think media attention of my work has been a positive force for getting undergraduate and graduate students to be interested in my research team (which is a lot of fun!). Evolution is a firecracker in modern media circles, and while this fact sometimes makes things politically difficult, it definitely creates positive attention for evolutionarily themed work among students (personal communication).

In spite of the widespread benefits of working with the media, one must be prepared for the time and energy media attention costs. When a story is reported by one media outlet, oftentimes several outlets also pick it up immediately afterwards, and sometimes the attention can spread globally. The best way, in our opinion, to cope with the potential number of interview requests is to work with a media relations office at one's institution. Once the interview requests start to arrive, one must be well prepared to talk about the work in a way that reporters can understand, but also potentially help the reporters by having "soundbites" that they can use. In order to maintain accurate reporting, as much as possible, one might want to work closely with reporters and authorize any final write-ups before they are printed (or recorded interviews released on the radio or television). Also, it is important to keep in mind that not all attention might be positive; one should be ready to deal at a personal level with negative comments, for example.

In spite of all of these costs, though, it remains our firm opinion that working with the media is an incredibly important function of evolutionary scholars. These individuals, many of whom are likely the readers of this paper, are in an especially critical position when it comes to educating those who are not students and those who may not have been formally exposed to evolutionary theory. All that currently exists for these individuals are mass trade books, which likely are read by those who are initially open to the ideas of evolution and willing to spend money to learn. It is therefore left to evolutionary scholars to educate beyond the university community, and one of the best means to do so is to use mass media outlets. We believe the EvoS Consortium is a promising start, and as it begins to ensure that evolutionary theory is properly represented across numerous campuses, and in many other domains, we must be prepared to take evolution beyond the university walls and out into the real world. To do so, our best allies there are those who make their bread and butter reporting information to the public as most academics report it to students: mass media reporters.

\section{References}

Berkman MB, Pacheco JS, Plutzer E. Evolution and creationism in America's classrooms: a national portrait. public library of science. Biology. 2008;6:e124. doi:10.1371/journal.pbio.0060124. Retrieved August 15, 2010.

Dawkins R. The God delusion. New York: Houghton Mifflin; 2006.

Dawkins R. The greatest show on earth: the evidence for evolution. New York: Free Press; 2009.

Fisher ML, Kruger DJ, Jobling I. Women's mating strategies and preferences of dads versus cads. Toronto: American Psychological Association; 2003.

Garcia J, Reiber C. Hook-up behavior: a biopsychosocial perspective. J Soc Evol Cult Psychol. 2008;2:192-208.

Garcia J, Geher G, Crosier B, Saad G, Gambacorta D, Johnsen L, Pranckitas E. The interdisciplinarity of evolutionary approaches to human behavior: a key to survival in the ivory archipelago. Futures, 2011.

O'Brien DT. "Evolution for everyone": a course that expands evolutionary theory beyond the biological sciences. Evolution: Education and Outreach. 2009;2:445-57.

Purrington C. http://www.swarthmore.edu/NatSci/cpurrin1/evolk12/ teaching/resources.htm Retrieved August 15; written April 2009.

Wilson DS. Evolution for everyone: how to increase acceptance of, interest in, and knowledge about evolution. Public library of science. Biology. 2005;3:e364. doi:10.1371/journal.pbio.0030364.

Wilson DS. Evolution for everyone: how Darwin's theory can change the way we think about our lives. New York: Delacorte; 2007.

Wilson DS, Geher G, Waldo J. EvoS: completing the evolutionary synthesis in higher education. EvoS Journal: The Journal of the Evolutionary Studies Consortium. 2009;1:3-10. 